\title{
The Relationship Between Cognitive Performance and Cardiorespiratory Fitness in Adolescents
}

\author{
Justė Knatauskaitė ${ }^{1}$, Kazimieras Pukẻnas ${ }^{1}$, Tomas Kentra ${ }^{2}$ \\ Lithuanian Sports University', Kaunas, Lithuania \\ Vytautas Magnus University Kaunas "Rasa” Gymnasium², Kaunas, Lithuania
}

\begin{abstract}
Background. Literature suggests cardiorespiratory fitness as a factor influencing cognitive improvement. The authors of the present study sought to investigate if cardiorespiratory fitness related to cognitive performance after an acute bout of game-based exercise of different intensities in adolescents.

Methods. As many as 37 adolescents ( 24 girls and 13 boys, 15-16 years of age) were assigned to three groups: experimental group 1 (EX 1), experimental group 2 (EX 2), and control (CON) group. The experimental groups experienced different levels of exercise intensity (EX 1 - light intensity, EX 2 - vigorous intensity). The Shuttle Run Test was performed a week before the intervention and $\mathrm{VO}_{2 \text { peak }}$ was calculated. Symbol Digit Modalities Test (SDMT) was evaluated before and after the acute intervention. A 2 × 3 repeated-measures ANOVA was used to analyse the SDMT and Pearson's correlation coefficient was used to estimate the relationship between the cognitive performance (SDMT) and cardiorespiratory fitness $\left(\mathrm{VO}_{2 \text { peak }}\right)$.

Results. Comparing the SDMT scores before and after the intervention, there were no differences found between the three groups. Neither in any of the experimental groups nor in the control group was a relationship between the SDMT score and $\mathrm{VO}_{2 \text { peak }}$ observed.

Conclusion. Acute game-based exercise intervention did not prove to improve cognitive performance effectively. The authors of the present paper did not confirm the relationship between cardiorespiratory fitness and cognitive performance in adolescents.
\end{abstract}

Keywords: exercise, cognitive performance, cardiorespiratory fitness.

\section{INTRODUCTION}

$\mathrm{E}$ xisting literature suggests that exercise influences cognitive functions (Chang et al., 2014; Zuniga, Mueller, Santana, \& Kelemen, 2019). While adolescents spend much of their time at school, school-based exercise intervention is an appropriate and cost-effective way $(\mathrm{Wu}$, Cohen, Shi, Pearson, \& Sturm, 2011) to improve cognitive and academic performance. Exercise is a planned and structured physical activity with a specific aim. Repeatedly performed exercise is called chronic exercise and a single bout of exercise - acute exercise (Budde et al., 2016). It is assumed that acute exercise induces neurochemical response, which, in turn, influences cognitive performance (Best, 2010).
There are findings suggesting cognitive functions to be enhanced with acute exercise at both light (Zuniga et al., 2019) and high (Budde et al., 2012) intensities. However, the above-mentioned studies analyzed the cognitive benefits in young adults and only one type of exercise - aerobic exercise.

Regarding the exercise type, cardiovascular and motor-demanding exercises enhance cognitive functions (Sibley \& Etnier, 2003) and especially when exercising in groups (Pesce, Crova, Cereatti, Casella, \& Bellucci, 2009). What is more, exercises, which bring pleasure and enjoyment, for example games, encourage children's participation (Thivel et al., 2011). 
Hence, game-based exercises of light and vigorous intensity were used in the present study.

Furthermore, there are findings that cardiorespiratory endurance is the most important factor of physical fitness related to cognitive functions (Ruiz-Ariza, Grao-Cruces, de Loureiro, \& Martinez-Lopez, 2017). Regular participation in physical activity improves cardiorespiratory fitness (Etnier, Nowell, Landers, \& Sibley, 2006), which may moderate the cognitive performance (Wengaard, Kristoffersen, Harris, \& Gundersen, 2017). Previous research highlights the impact of cardiorespiratory endurance on brain activity and cognition across the lifespan (Themanson, Pontifex, \& Hillman, 2008). For example, Westfall et al. (2018) reported better inhibitory control and cognitive flexibility for adolescents with higher cardiovascular fitness. Moreover, a review carried out by Alvarez-Bueno et al. (2020) summarized the evidence explaining the association between aerobic fitness and language as well as mathematics related skills. However, most of the aforementioned studies are non-interventional and the relationship between cardiorespiratory fitness and cognitive performance after the acute exercise intervention remains unknown.

Overall, this study aimed to compare the acute effect of light and vigorous intensity gamebased exercises on cognitive performance in adolescents and determine if this effect is related to cardiorespiratory fitness. The authors of the present study hypothesized that cardiorespiratory fitness would be related to cognitive performance after a bout of game-based exercises.

\section{METHODS}

Participants. We assigned 37 adolescents (24 girls; 13 boys; $15-16$ years old) to one of the following groups: the control group $(\mathrm{n}=12)$ $(\mathrm{CON})$, experimental group $1(\mathrm{EX} 1)(\mathrm{n}=13)$, and experimental group 2 (EX 2) $(n=12)$. The basic characteristics of the participants are listed in Table 1. Inclusion criteria were the absence of physical and mental impairments and no usage of psychotropic medications. Adolescents signed informed assent forms and their parents signed informed consent forms in accordance with the Declaration of Helsinki. The study was approved by Kaunas Regional Committee on Biomedical Research Ethics (No. BE-2-68).
Table 1. Mean values (SD) for the basic characteristics of two experimental groups (EX 1 and EX 2) and control (CON) group

\begin{tabular}{|l|c|c|c|}
\hline \multicolumn{1}{|c|}{ Characteristic } & CON & EX 1 & EX 2 \\
\hline Age (years) & $14.92(0.29)$ & $15.46(0.52)$ & $15.17(0.39)$ \\
\hline $\mathrm{BMI}\left(\mathrm{kg} / \mathrm{m}^{2}\right)$ & $20.77(1.99)$ & $20.84(1.97)$ & $20.42(1.44)$ \\
\hline Tanner (stage) & $3.67(0.49)$ & $3.77(0.60)$ & $3.92(0.79)$ \\
\hline $\begin{array}{l}\mathrm{VO}_{2 \text { peak }} \\
(\mathrm{mL} / \mathrm{kg} / \mathrm{min})\end{array}$ & 36.95 & 34.93 & 35.55 \\
\hline
\end{tabular}

Note. CON - control group; EX 1 - experimental group 1; EX 2 experimental group 2 .

Procedure. One week before the experiment, the participants performed the necessary tests for background information according to the study protocol: height, weight, pubertal maturation and Shuttle Run Test. Also, $\mathrm{VO}_{\text {2peak }}$, as an indicator of cardiorespiratory fitness, was calculated. They were familiarized with the intervention and testing procedures during the experiment. On the experiment day, the Symbol Digit Modalities Test (SDMT) was performed before and after the intervention.

The intervention lasted $20 \mathrm{~min}$. Participants in both experimental groups performed exercises usually in the form of a relay game. The exercises required body balance, spatial orientation, and motor skills management. The difference between the experimental groups was the exercise intensity. The heart rate during the intervention was measured and the exercise intensity was evaluated according to the percentage of maximum heart rate $\left(H R_{\max }\right) . H R_{\max }$ was calculated using the following formula: $208-0.7 \mathrm{x}$ age. The EX 1 intensity was light $\left(58.64 \% \mathrm{HR}_{\max }\right)$ and the EX 2 intensity was vigorous $\left(89.51 \% \mathrm{HR}_{\max }\right)$ according to Garber et al. (2011).

The control group condition consisted of being sedentary for $20 \mathrm{~min}$ in a school classroom; the students were not allowed to talk to each other.

Measurements. Height was measured to the nearest $0.1 \mathrm{~cm}$ using a Harpenden anthropometer set (Holtain, Crymych, Dyfed, Wales, UK). Weight and body mass index were measured using a body composition scale (TBF-300; Tanita, UK).

Pubertal maturation was assessed according to the Tanner stages using drawings of breasts, genitals, and pubic hair. This self-assessment tool can be used to distinguish prepuberty and puberty (Rasmussen et al., 2015). 
The heart rate of the participants was measured using a heart rate monitor (Polar FT1, Kempele, Finland).

The written form of the SDMT was used to evaluate attention, motor speed, and visual scanning. It is a paper-pencil test, which is useful to administrate in a group of people and does not require special devices. Also, it is one of the tasks showing an improvement after an acute exercise (Basso \& Suzuki, 2017). Participants were given 9 pairs of symbols and numbers (1-9). There were 110 boxes with the symbols and free spaces for numbers. The instruction was to write the numbers in free spaces according to paired symbols given at the top of the page. Participants were allowed 90 $\mathrm{s}$ to complete the task. Correct substitutions were counted (Sheridan et al., 2006).

Shuttle Run Test. A participant has to run between 2 lines (20 meters between each) back and forth with the intensity increasing. The rate is regulated according to the acoustic signal. The speed is $8 \mathrm{~km} / \mathrm{h}$ at the beginning, and it increases by $0,5 \mathrm{~km} / \mathrm{h}$ every minute. If a participant cannot keep the pace for two consecutive signals, the test is stopped and the level and number of shuttles are noted (Freedson, Cureton, \& Heath, 2000).
The following equation was used to estimate $\mathrm{VO}_{2 \text { peak }}$ from the 20 -m shuttle-run test: $\mathrm{VO}_{2 \text { peak }}=$ $25.8-6.6 \times \mathrm{G}-0.2 \times \mathrm{BM}+3.2 \times \mathrm{S}(\mathrm{G}-$ gender $($ male $=0$, female $=1) ; \mathrm{BM}-$ body mass $(\mathrm{kg}) ; \mathrm{S}-$ speed at the end of the test $(\mathrm{km} / \mathrm{h}))($ Moreira et al., 2011).

Statistical analysis. Statistical procedures were conducted using IBM SPSS for Windows (version 26.0; IBM, Armonk, NY, USA). A 2 x 3 repeatedmeasures ANOVA was used to analyze the SDMT. Partial $\eta^{2}$ effect sizes were calculated together with observed power $(O P)$. Pearson's correlation coefficient was used to evaluate the relationship between variables with the effect size $r(.1$ to $.29=\mathrm{a}$ small relationship; .3 to $.49=$ a medium relationship; .5 to $1.0=$ a large relationship). For all statistical analyses, the significance level was $\alpha=.05$.

\section{RESULTS}

SDMT performance. The descriptive statistics of the SDMT are shown in Table 2. The authors of the present study found a significant effect of time $\left(\mathrm{F}_{1}=30.96, p=.000, \eta^{2}=.48, O P=1.00\right)$. There was no effect of the group $\left(\mathrm{F}_{2}=0.23, p=.798\right.$, $\left.\eta^{2}=.01, O P=0.08\right)$ or time-group interaction $\left(\mathrm{F}_{2}=0.50, p=.612, \eta^{2}=.03, O P=0.13\right)$.

Table 2. Mean (SD) for pre-test and post-tes SDMT values in two experimental groups (EX 1 and EX 2) and the control group (CON)

Notes. CON - control group; EX 1 experimental group 1; EX 2 - experimental group 2; SDMT - Symbol Digit Modalities Test; $p$-values were calculated via a repeated measures ANOVA (time effect) and one-way ANOVA (group effect)

\begin{tabular}{|l|c|c|c|c|}
\hline Variable & $\begin{array}{c}\text { CON } \\
(\boldsymbol{n}=\mathbf{1 2})\end{array}$ & $\begin{array}{c}\text { EX 1 } \\
(\boldsymbol{n}=\mathbf{1 3})\end{array}$ & $\begin{array}{c}\text { EX 2 } \\
(\boldsymbol{n}=\mathbf{1 2})\end{array}$ & $\begin{array}{c}\text { Group effect } \\
\boldsymbol{p} \text { value }\left(\boldsymbol{\eta}^{2}\right)\end{array}$ \\
\hline $\begin{array}{c}\text { SDMT (score) } \\
\text { Before }\end{array}$ & $52.00(5.59)$ & $51.08(6.20)$ & $53.67(9.69)$ & $.680(.02)$ \\
After & $57.27(8.97)$ & $59.00(7.25)$ & $59.58(10.92)$ & $.901(.01)$ \\
\hline $\begin{array}{c}\text { Time effect } \\
p \text {-value }\left(\eta^{2}\right)\end{array}$ & $.039(.33)$ & $<.001(.73)$ & $.010(.45)$ & \\
\hline
\end{tabular}

Figure. Relationship between cardiorespiratory fitness $\left(\mathrm{VO}_{2 \text { peak }}\right)$ and the overall change in Symbol Digit Modalities Test (SDMT) performance after an acute bout of gamebased exercises in the control (CON), light intensity (LIG) and vigorous intensity group (VIG)

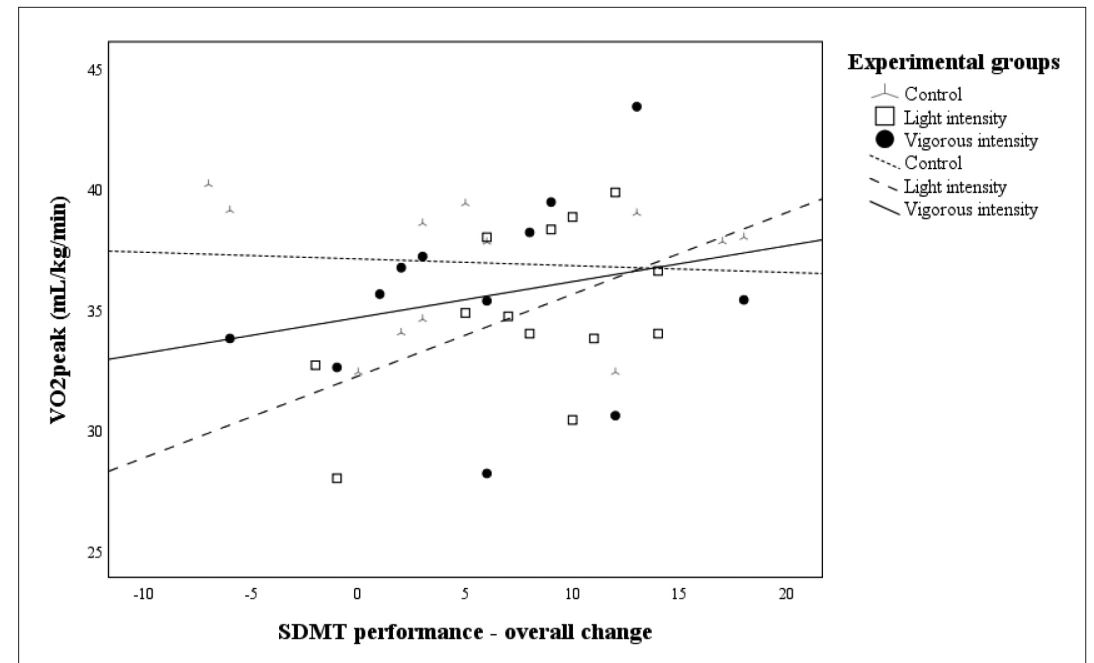




\section{Relationship between SDMT performance and cardiorespiratory fitness. Pearson's} correlation coefficient was calculated between the overall change of SDMT scores and $\mathrm{VO}_{2 \text { peak }}$ values. However, there were no relevant correlations between these two variables in both experimental groups (EX 1: $p=.084, r=.50$; EX 2: $p=.443$, $r=.25)$ and the $\operatorname{CON}(p=.801, r=-.08)$ (Figure).

\section{DISCUSSION}

The authors of the present study aimed to investigate the effect of acute game-based exercise of different intensities on cognitive performance and if it is related to cardiorespiratory fitness $\left(\mathrm{VO}_{\text {2peak }}\right)$. They did not confirm the relationship between cardiorespiratory fitness and cognitive performance after the acute game-based exercise in adolescents.

SDMT performance. The results of the present study revealed that there was no difference between any of the groups comparing the results of the SDMT. These findings are contrary to other studies where the light (Zuniga et al., 2019) and vigorous (Budde et al., 2012) intensity aerobic exercises improved the cognitive function. One of the explanations could be the exercise type, which is important for exercise efficiency (Gronwald, Törpel, Herold, \& Budde, 2020). In addition, there is a possible learning effect (Stieger \& Reips, 2016), even though the participants were familiarized with the testing procedure. However, previous meta-analysis showed no effect of active school breaks on cognition (Masini et al., 2019). Thus, the effect of acute game-based exercise on cognitive performance in adolescents needs further investigation.

Relationship between SDMT performance and cardiorespiratory fitness. There was no relationship between cardiorespiratory fitness and cognitive performance (SDMT) after the acute game-based exercise intervention. The findings of this paper did not support the previous studies showing a positive association between cardiorespiratory fitness and cognitive functions (Themanson et al., 2008; Westfall et al., 2018). On the other hand, the study carried out by Chang et al. (2014) showed an improvement in cognitive performance after an acute aerobic exercise of moderate intensity in participants of all fitness levels. However, the participants were young adults and the exercise type and intensity were different comparing to the present study. Similarly, Niemann et al. (2013) stated that a short bout of intensive physical activity had a beneficial effect on cognitive performance in preadolescent children independent of their physical activity level. Thus, future research that continues to analyze the relationship between the cardiorespiratory fitness and cognitive performance in adolescents is warranted.

Limitations. First, there was a small sample size and the results should be interpreted with caution. Second, there was a possible learning effect in the analysis of cognitive performance. Finally, the cardiorespiratory fitness was not evaluated directly in a laboratory using a ergospirometric device.

\section{CONCLUSIONS}

1. There were no differences between the experimental groups and the control group in terms of the results of cognitive performance before and after the acute game-based exercise intervention in adolescents.

2. Cardiorespiratory fitness was not related to cognitive performance after the acute gamebased exercise intervention in adolescents.

Acknowledgements. The authors are grateful to Rūta Šiaudvytyte for providing help with the English language.

\section{REFERENCES}

Álvarez-Bueno, C., Hillman, C. H., Cavero-Redondo, I., Sánchez-López, M., Pozuelo-Carrascosa, D. P., \& Martínez-Vizcaíno, V. (2020). Aerobic fitness and academic achievement: A systematic review and metaanalysis. Journal of Sports Sciences, 38(5), 582-589. doi: 10.1080/02640414.2020.1720496

Basso, J. C., \& Suzuki, W. A. (2017). The effects of acute exercise on mood, cognition, neurophysiology, and neurochemical pathways: A review. Brain Plasticity
(Amsterdam, Netherlands), 2(2), 127-152. doi: 10.3233/ BPL-160040

Best, J. R. (2010). Effects of physical activity on children's executive function: Contributions of experimental research on aerobic exercise. Developmental Review, 30(4), 331-551. doi: 10.1016/j.dr.2010.08.001

Budde, H., Brunelli, A., Machado, S., Velasques, B., Ribeiro, P., Arias-Carrión, O., \& Voelcker-Rehage, C. (2012). Intermittent maximal exercise improves 
attentional performance only in physically active students. Archives of Medical Research, 43(2), 125-131. doi: 10.1016/j.arcmed.2012.02.005

Budde, H., Schwarzc, R., Velasques, B., Ribeiro, P., Holzweg, M., Machado, S., ... Wegner, M. (2016). The need for differentiating between exercise, physical activity, and training. Autoimmunity Reviews, 15(1), 110-111. doi: 10.1016/j.autrev.2015.09.004

Chang, Y. K., Chi, L., Etnier, J. L., Wang, C. C., Chu, C. H., \& Zhou, C. (2014). Effect of acute aerobic exercise on cognitive performance: Role of cardiovascular fitness. Psychology of Sport and Exercise, 15(5), 464-470. doi: 10.1016/j.psychsport.2014.04.007

Etnier, J. L., Nowell, P. M., Landers, D. M., \& Sibley, B. A. (2006). A meta-regression to examine the relationship between aerobic fitness and cognitive performance. Brain Research Reviews, 52(1), 119-130. doi: 10.1016/j.brainresrev.2006.01.002

Freedson, P. S., Cureton, K. J., \& Heath, G. W. (2000). Status of field-based fitness testing in children and youth. Preventive Medicine, 31(2), S77-S85. doi: 10.1006/ pmed.2000.0650

Garber, C. E., Blissmer, B., Deschenes, M. R., Franklin, B. A., Lamonte, M. J., Lee, I. M., ... Swain, D. P. (2011). American college of sports medicine position stand. quantity and quality of exercise for developing and maintaining cardiorespiratory, musculoskeletal, and neuromotor fitness in apparently healthy adults: Guidance for prescribing exercise. Medicine \& Science in Sports \& Exercise, 43(7), 1334-1359. doi: 10.1249/ MSS.0b013e318213fefb

Gronwald, T., Törpel, A., Herold, F., \& Budde, H. (2020). Perspective of dose and response for individualized physical exercise and training prescription. Journal of Functional Morphology and Kinesiology, 5(3), 48. doi: 10.3390/jfmk5030048.

Masini, A., Marini, S., Gori, D., Leoni, E., Rochira, A., \& Dallolio, L. (2019). Evaluation of school-based interventions of active breaks in primary schools: A systematic review and meta-analysis. Journal of Science and Medicine in Sport, 23(4), 377-384. doi: 10.1016/j. jsams.2019.10.008

Moreira, C., Santos, R., Ruiz, J. R., Vale, S., SoaresMiranda, L., Marques, A. I., \& Mota, J. (2011). Comparison of different $\mathrm{VO}_{2} \max$ equations in the ability to discriminate the metabolic risk in Portuguese adolescents. Journal of Science and Medicine in Sport, 14(1), 79-84. doi: 10.1016/j.jsams.2010.07.003

Niemann, C., Wegner, M., Voelcker-Rehage, C., Holzweg, M., Arafat, A. M., \& Budde, H. (2013). Influence of acute and chronic physical activity on cognitive performance and saliva testosterone in preadolescent school children. Mental Health and Physical Activity, 6(3), 197-204. doi: 10.1016/j.mhpa.2013.08.002

Pesce, C., Crova, C., Cereatti, L., Casella, R., \& Bellucci, M. (2009). Physical activity and mental performance in preadolescents: Effects of acute exercise on free-recall memory. Mental Health and Physical Activity, 2(1), 16-22. doi: 10.1016/j.mhpa.2009.02.001

Rasmussen, A. R., Wohlfahrt-Veje, C., de RenzyMartin, K. T., Hagen, C. P., Tinggaard, J., Mouritsen, A., ... Main, K. M. (2015). Validity of self-assessment of pubertal maturation. Pediatrics, 135(1), 86-93. doi: 10.1542/peds.2014-0793

Ruiz-Ariza, A., Grao-Cruces, A., de Loureiro, N. E. M., \& Martinez-Lopez, E. J. (2017). Influence of physical fitness on cognitive and academic performance in adolescents: A systematic review from 2005-2015. International Review of Sport and Exercise Psychology, 10(1), 108-133. doi: 10.1080/1750984X.2016.1184699

Sheridan, L. K., Fitzgerald, H. E., Adams, K. M., Nigg, J. T., Martel, M. M., Puttler, L. I., ... Zucker, R. A. (2006). Normative symbol digit modalities test performance in a community-based sample. Archives of Clinical Neuropsychology, 21(1), 23-28. doi: 10.1016/j. acn.2005.07.003

Sibley, B. A., \& Etnier, J. L. (2003). The relationship between physical activity and cognition in children: A meta-analysis. Pediatric Exercise Science, 15(3), 243256. doi: 10.1515/ijsl.2000.143.183

Stieger, S. \& Reips, U. (2016). A limitation of the Cognitive Reflection Test: Familiarity. Peer Journal, 4, e2395. doi: 10.7717/peerj.2395

Themanson, J. R., Pontifex, M. B., \& Hillman, C. H. (2008). Fitness and action monitoring: Evidence for improved cognitive flexibility in young adults. Neuroscience, 157(2), 319-328. doi: 10.1016/j. neuroscience.2008.09.014

Thivel, D., Isacco, L., Lazaar, N., Aucouturier, J., Ratel, S., Doré, E., ... Duché, P. (2011). Effect of a 6-month school-based physical activity program on body composition and physical fitness in lean and obese schoolchildren. European Journal of Pediatrics, 170(11), 1435-1443. doi: 10.1007/s00431-011-1466-X

Wengaard, E., Kristoffersen, M., Harris, A., \& Gundersen, H. (2017). Cardiorespiratory fitness is associated with selective attention in healthy male highschool students. Frontiers in Human Neuroscience, 11, 330. doi: 10.3389/fnhum.2017.00330

Westfall, D. R., Gejl, A. K., Tarp, J., Wedderkopp, N., Kramer, A. F., Hillman, C. H., \& Bugge, A. (2018). Associations between aerobic fitness and cognitive control in adolescents. Frontiers in Psychology, 9, 1298. doi: 10.3389/fpsyg.2018.01298

Wu, S., Cohen, D., Shi, Y., Pearson, M., \& Sturm, R. (2011). Economic analysis of physical activity interventions. American Journal of Preventive Medicine, 40(2), 149-158. doi: 10.1016/j.amepre.2010.10.029

Zuniga, K. E., Mueller, M., Santana, A. R., \& Kelemen, W. L. (2019). Acute aerobic exercise improves memory across intensity and fitness levels. Memory, 27(5), 628-636. doi: 10.1080/09658211.2018.1546875 